\title{
Association between physical activity and activity space in different farming seasons among rural Lao PDR residents
}

Hongwei Jiang ${ }^{1 *} \mathbb{D}$, Lin Lin², Daniel Anthony Yonto ${ }^{3}$, Tiengkham Pongvongsa ${ }^{4}$, Sengchanh Kounnavong ${ }^{5}$ and Kazuhiko Mojí

\begin{abstract}
Background: Southeast Asia is experiencing a health transition, where non-communicable diseases (NCD) are exceeding communicable diseases. Despite NCDs accounting for roughly $60-85 \%$ of deaths in the region, many developing Southeast Asian countries are beginning to address the impacts of a physically inactive lifestyle for the first time. Our study aims to bridge this gap by objectively measuring physical activity in rural Lao PDR to reveal the association among physical activity, activity space, and seasonal variation.
\end{abstract}

Methods: Multiple waves of survey data were collected in Songkhon District, Lao PDR between March 2010 and March 2011. Adults aged between 18 and 65 were recruited $(n=48)$. A portable GPS recorded participants' activity and farmland locations and an accelerometer recorded participants' physical activity level and daily steps for seven consecutive days. Using a directional distribution tool in ArcGIS 10.5, the activity space area of each participant in each wave was calculated. Concurrently, participants recorded time spent on each daytime activity. Linear mixed models with the fixed effects as the observations from different waves and the random effects as individual participants were developed to identify factors associated with areas of activity space and counts of daily steps, respectively.

Results: A total of 48 respondents aged between 19 and 57 took part in the study. Half of the participants were females. Walking was found to be the most frequent travel mode. Females were physically less active, with a smaller activity space, and were more overweight than the males in the study. Participants were physically less active during the off-farming seasons.

Conclusions: Findings contribute to the surveillance of risk factors needed to create healthy living environments. Our research is also one of the first to use empirical evidence demonstrating seasonal variations of rural residents' activities in mainland Southeast Asia.

Keywords: Physical activity, Activity space, Rural Lao PDR, GPS and accelerometer, Farming seasons

\section{Background}

Southeast Asia is experiencing a health transition, where non-communicable diseases (NCD) are exceeding communicable diseases [1]. In 2016, NCDs accounted for

*Correspondence: jiang@chikyu.ac.jp

${ }^{1}$ Research Institute for Humanity and Nature, 457-4 Motoyama, Kamigamo, Kita-ku, Kyoto 603-8047, Japan

Full list of author information is available at the end of the article roughly $60-85 \%$ of deaths across the region $[1,2]$, with physical inactivity responsible for approximately $3.2 \%$ of the disease burden [3]. One of the main challenges associated with physical inactivity is that it decreases energy expenditure, which increases the epidemic of overweight and obesity [3-5]. A physically inactive lifestyle also leads to higher morbidity rates from cardiovascular disease, ischemic stroke, and metabolic syndrome [3, 
6]. Although physical inactivity is a common concern in developed countries [7], many developing countries in Southeast Asia are beginning to note the impacts of a physically inactive lifestyle for the first time [8] as overweight and obesity concerns start to rise [2,9-11].

One of the primary data collection instruments in social, health, and epidemiological research is the survey questionnaire [12]. Using subjective methods, such as the International Physical Activity Questionnaire (IPAQ) or Global Physical Activity Questionnaire (GPAQ), these surveys assess the physical activity level of the population in developing countries [5, 13, 14]. However, objective measures using pedometers or accelerometers provide a more precise and valid measures of time spent in various physical activities [15-18]. Objective measures are used less often in developing countries due to financial constraints or a lack of expertise managing the technology $[19,20]$. Thus, the lack of objective physical activity data from developing countries is a significant barrier in advocating public health interventions with cultural and environmental sensitivity to improve physical activity in chronic disease prevention.

Activity space can be quantified through several measures [21-27]. Several transportation studies used data from the time-space diary technique; however, this requires a high degree of commitment and collaboration with participants $[28,29]$, which makes replicating these studies in rural Southeast Asia challenging due to the subsistence lifestyles of its residents. Compared to traditional travel diaries and questionnaires, global positioning system (GPS) tracking devices enhance the ability and reliability of collecting large amounts of trajectory data. As a result, the overall data quality has been greatly improved. At the same time, activity space measured by GPS and step count by accelerometer/pedometer has been increasingly used in physical activity studies to examine the associations between environments and activity [30,31]. The spaces within which people actually move and are exposed to could explain inter- and intrapersonal variations in spatial habits [30]. Hence, understanding activity space could help explain different levels of physical activity.

Environmental factors are expected to be related to physical activity in multiple life domains: leisure/recreation/exercise, occupation, transportation, and household [32]. To identify the association between environment or activity space and physical activity, considerable research has been conducted through a GPS and a geographic information system merged with accelerometer data [3336]. Although most activity space research is conducted in developed countries, developing countries provide a unique set of challenges that remain understudied [37]. Developing countries in Southeast Asia differ in their built environment, economic activities, seasonal changes, and cultural norms from developed countries in the west [38]. Thus, solutions aimed at increasing physical activity in developed countries, such as parks or sidewalks, may not be effective or directly applicable to developing countries [39].

To this end, our study uses GPS and accelerometer devices to objectively measure physical activity in rural Lao PDR. In doing so, we aim to reveal the association among physical activity, activity space, and seasonal variation in this understudied region. Our results contribute to the surveillance of risk factors needed to create environments that are conducive to healthy living in Southeast Asia and baseline information of activity changes in rural Laos [2].

\section{Methods}

Study area

This study was conducted in Songkhon District, Savannaket Province, Lao PDR (Fig. 1), located near Lahanam, which is situated along the Bang Hiang River, a branch of the Mekong River. The climate is considered tropical monsoon, where the wet season lasts from April to October. The average seasonal temperature is about $27^{\circ} \mathrm{C}$ with an average rainfall of roughly $1390 \mathrm{~mm}$ during the wet season. The dry season starts from November and ends in March with an average seasonal temperature of $23{ }^{\circ} \mathrm{C}$ and an average precipitation of roughly $73 \mathrm{~mm}$ (Unpublished records of Savannakhet Provincial Meteorological Section). The village has a total population of 1091 registered residents, with 628 between 18 and 65 years as of March 1, 2010 (Village Chief notes). The actual adults who lived in the village fluctuated during the time of our study due to about $30 \%$ of the population participating in seasonal work in Thailand and Vientiane (capital of Lao PDR).

A typical family in Lahanam earns a living by rice cultivating, livestock grazing, fishing, and cloth weaving. In general, livestock grazing is the work of male adults and weaving is the work of female adults (Unpublished observations). However, both female and male adults engage in fishing year-round (Unpublished observation). Consistent with other regions of Lao PDR, rice cultivation is the major subsistence of local residents [40].

Our study area has roughly four farming seasons: wet farming, wet off-farming, dry farming, and dry off-farming. Two types of rice cultivation are carried out in the wet and dry seasons. The wet season rice cultivation, which is rain-fed, starts from May and is harvested in October [40]. The dry season cultivation is carried out in sections of the rice paddy with irrigation from December to April. The drastic differences in precipitation between wet and dry seasons have a direct impact on individual 


\section{Songkhon District and Lahanam area}

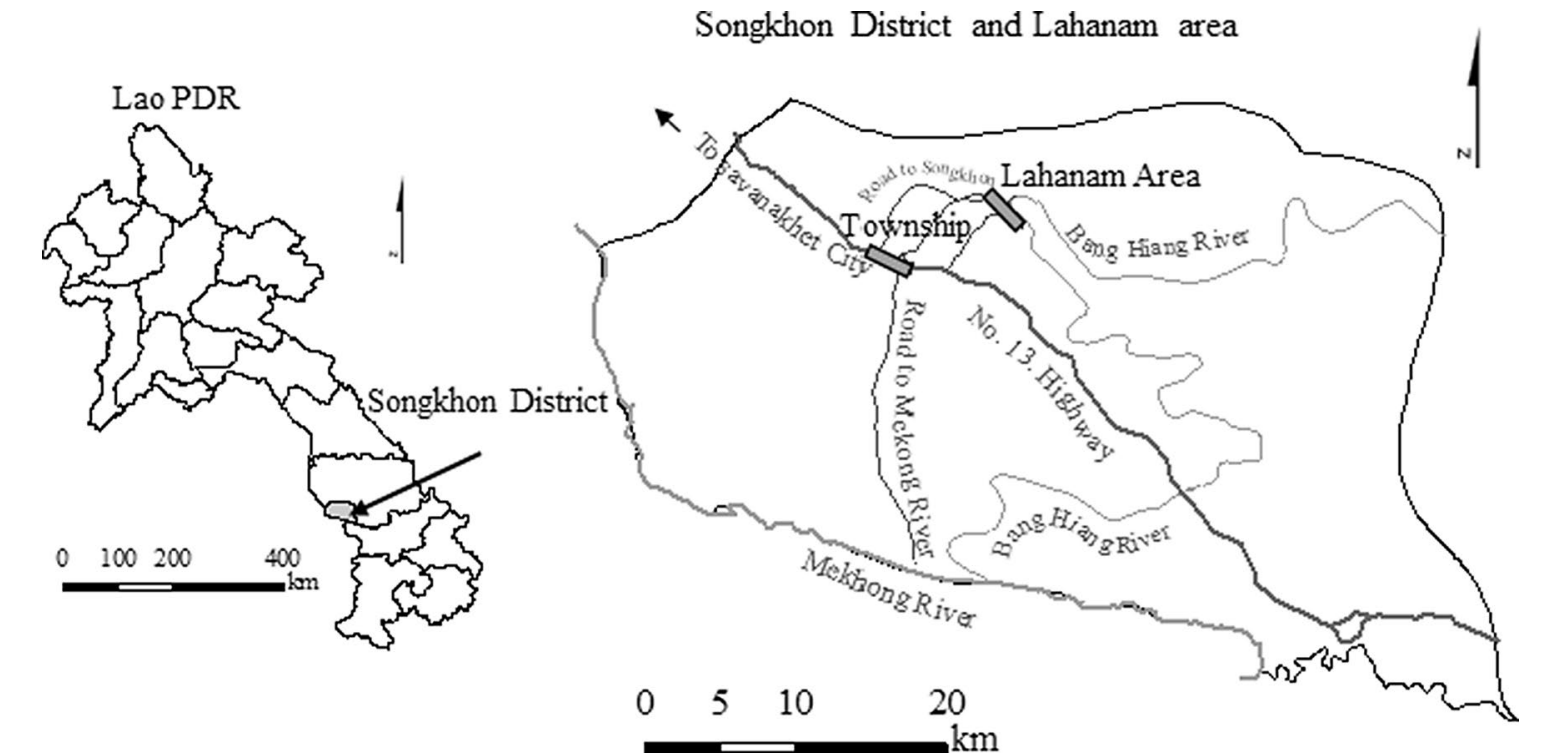

Fig. 1 Lahanam area in Songkhon District, Lao PDR. The target village, located inside the rectangular shape labeled as Lahanam Area on the map, is situated along the west bank of the Bang Hiang River (This map was created by the authors)

activities. To that end, our survey is predicated on the four seasons based around Lahanam's farming activities.

\section{Data collection}

To capture the seasonal activity changes of local residents, multiple waves of surveys were carried out in Lahanam from June 2010 to March 2011. In each wave, two devices were used to collect data for each participant for seven consecutive days. The first, a portable GPS device (M241, Holux Technology, Inc.), recorded activity and farmland location of participants. The second, an accelerometer instrument (Lifecorder EX, Suzuken Ltd.), measured the participant's physical activity level and steps. Recording was made every twelve seconds for the GPS and 2 min for the accelerometer. Concurrently, a self-reported log by each participant detailed the time spent on each activity from 6 am to $6 \mathrm{pm}$. The body weight and height of each participant was measured in each wave by the researchers. GPS data were validated by the accelerometer and, if no record existed in the accelerometer, or if GPS data did not agree with accelerometer data, we excluded the data.

To test the GPS devices battery and the waterproofness of the device shell in the study area, 20 participants, 10 males and 10 females aged between 18 and 65 years, were recruited by convenience sampling through the village head in March 2010. The formal data collection started from June 2010. Due to the availability of the devices, about 30 able-bodied adults aged between 18 and 65 (pregnant women were excluded as well) were recruited each wave from Wave 1 to Wave 4. Not all participants completed all four waves to covered four different farming seasons, namely, wet farming season (Wave 1: June 2010), wet off-farming season (Wave 2: September 2010), dry farming season (Wave 3: December 2010) and dry off-farming season (Wave 4: March 2011). Twenty thousand Lao kips (USD \$2.50) was given to each participant who completed one wave, with a total of 100,000 Lao kips (USD \$12.5) given to participants who completed all five survey waves. Wave 1 to Wave 4 were included in the further analyses.

Neighborhood built environment attributes were derived from google maps and QuickBird satellite image which was taken on January 9, 2008. Euclidean distances from participant's home to different types of land uses, such as paddy, the health center, the primary school, the middle school, the local market, the temple, and the mini shop in the village were measured to identify different destinations, where residents frequently visited.

\section{Creating activity space}

The most common method to operationalize activity space is the standard deviation ellipse (SDE) that measures the directional distribution of a series of GPS points or the "densest" areas, where most of the individual mobility occurs [41]. In this study, for each participant in each wave, activity space was delineated as an ellipse centered at the home and extended to two standard deviations of the observed activity locations that were recorded by the GPS device worn by each participant 


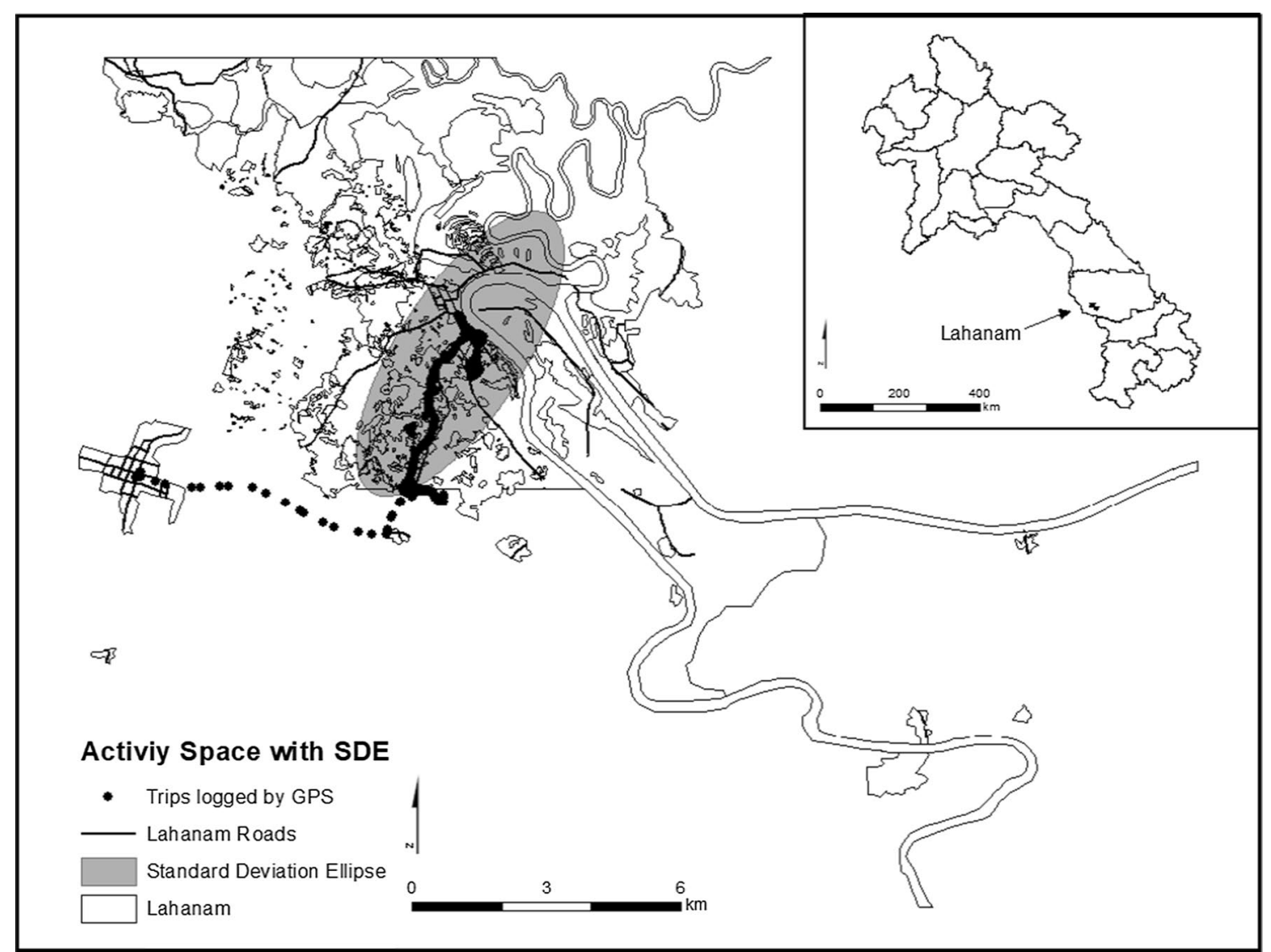

Fig. 2 Example of a participant's daily activity movement with a 2-standard deviation ellipse representing the participant's activity space shaded in gray (This map was created by the authors)

(see Fig. 2 for a participant's 1-day activity). The area of each activity space was calculated using a directional distribution tool in ArcGIS 10.5. The tool summarized spatial characteristics and created an SDE polygon as the output activity space. A 1-, 2-, and 3-SDE polygon was computed to cover $68 \%, 95 \%$, and $99 \%$ of the input features, respectively. Considering that a $1-\mathrm{SDE}$ covers $68 \%$ of activity points, several participants' activity space may not be constructed accurately using the 1-SDE approach. Conversely, using a 3-SDE may include outliers that distort the shape of the ellipse and introduce concerns that could result in measuring the extreme extent of travel and capture large geographic areas that are not visited by an individual. Therefore, our study used a 2-SDE polygon to delineate activity space in line with previous research [42].

\section{Statistical analysis}

Bivariate analysis of variables derived from the daytime activity log, and distance measures of land use were carried out with areas of activity space and counts of daily steps. Furthermore, ANOVA tests controlling for different waves were conducted for the two dependent variables by gender, and the self-reported time for different activities by gender by wave, respectively. Linear mixed models with the fixed effects as the observations from different waves and the random effects as individual participants were developed to identify factors associated with areas of activity space and counts of daily steps, respectively. Maximum likelihood (ML) and restricted maximum likelihood (REML) estimation were applied in estimating variance and covariance parameters in the linear mixed models. SPSS software (version 22.0) was used for all statistical analysis.

\section{Results}

\section{Descriptive statistics}

Table 1 summarizes participant's individual characteristics, daytime activity log, and distance from participant's home to different destinations in the village. A total of 48 participants between 19 and 57 years took part in the four waves of the study. Half of the participants [24] were females. The average age of the 


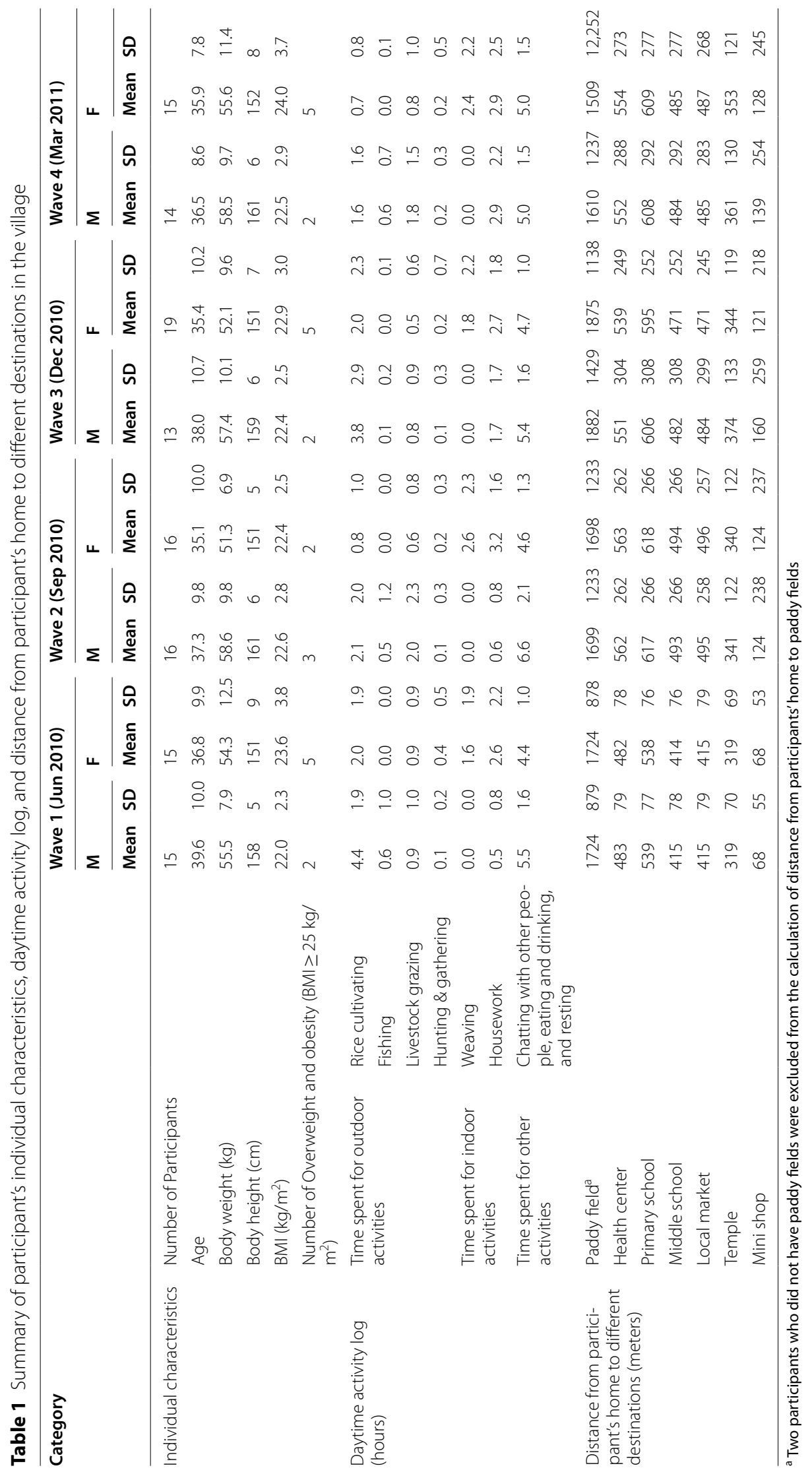


participants was $36 .{ }^{1}$ The average body mass index (BMI) of participants was $22.7 \mathrm{~kg} / \mathrm{m}^{2}$. One-fourth of the female participants were overweight with BMIs more than $25 \mathrm{~kg} / \mathrm{m}^{2}$, and one eighth of male participants were overweight. On average, 31 participants took part in each wave. Only six participants finished all four waves, while 22 and 13 participants did three and two waves of four waves, respectively, and seven participants one wave only.

Among all participants, two participants did not have farmland. The Euclidean distances of the remaining participants' farmland to their homes ranged between 65 and $4808 \mathrm{~m}$, with an average of $1729 \mathrm{~m}$. The average distances from participant's home to health center, primary school, middle school, local market, temple, and mini shop are $532 \mathrm{~m}, 588 \mathrm{~m}, 464 \mathrm{~m}, 465 \mathrm{~m}, 337 \mathrm{~m}$, and $109 \mathrm{~m}$, respectively.

The average sizes of the activity space were $29.6 \mathrm{~km}^{2}$, $16.9 \mathrm{~km}^{2}, 9.5 \mathrm{~km}^{2}$, and $37.9 \mathrm{~km}^{2}$ for wet farming season (Wave 1), wet off-farming season (Wave 2), dry farming season (Wave 3), and dry off-farming season (Wave 4 ), respectively. The average daily steps for Waves 1,2 , 3 , and 4 are $16,861,13,205,14,736$, and 13,297 , respectively. There were three female participants with average daily steps fewer than 10,000 steps-a conventional threshold for inactive lifestyle [43, 44] -in Wave 1, five females and two males with average daily steps fewer than 10,000 steps in Wave 2, and four females in Wave 3 and six females in Wave 4 with average daily steps fewer than 10,000. Table 2 summarizes the size of activity space and counts of daily steps by gender for each wave.

\section{Bivariate analysis}

To compare activity space and total steps between female and male, natural logarithm transformation was carried out for the area of each activity space and each participant's counts of daily steps. Table 3 summarizes the natural logarithm transformation of areas of activity space and total counts of steps by wave and by gender and ANOVA test results. ANOVA tests showed that the area of activity space is significantly different between females and males for Waves 1 and 4 . The counts of daily steps are significantly different between females and males throughout all waves. ANOVA tests were also conducted for self-reported time spent on different activities by gender for each wave. Table 4 summarizes the ANOVA

\footnotetext{
${ }^{1}$ Due to the lack of the Census data at the rural villages in Laos, we carried out our own population count with the help of the village head in the study area before the formal data collection started. Comparing the sampled residents and the residents aged between 18 and 65 who did not include in our survey, no significant differences were shown in terms of age (36.2 \pm 9.6 vs. $35.0 \pm 13.1, \mathrm{t}(547)=-0.557, \mathrm{p}=0.557)$ and the sex ratio $(50 \%$ vs. $46.9 \%$, $\mathrm{X}^{2}(1)=0.168, \mathrm{p}=0.682$ )
}

Table 2 Activity space and daily steps by gender and by wave

\begin{tabular}{|c|c|c|c|c|c|}
\hline \multirow[t]{2}{*}{ Wave } & & \multicolumn{2}{|c|}{ Female } & \multicolumn{2}{|l|}{ Male } \\
\hline & & Mean & SD & Mean & SD \\
\hline \multirow{3}{*}{$\begin{array}{l}\text { Wave } 1 \\
\text { (Jun 2010) }\end{array}$} & Activity area ${ }^{a}$ & 6.9 & 8.8 & 52.3 & 125.8 \\
\hline & Steps ${ }^{b}$ & 12.9 & 2.9 & 20.8 & 5.8 \\
\hline & No. of persons & 15 & & 15 & \\
\hline \multirow[t]{3}{*}{$\begin{array}{l}\text { Wave } 2 \\
\text { (Sep 2010) }\end{array}$} & $\begin{array}{l}\text { Activity area } \\
\text { Area }\left(\mathrm{km}^{2}\right) \text { area }\left(\mathrm{km}^{2}\right)\end{array}$ & 8.6 & 21.1 & 25.2 & 42.0 \\
\hline & Steps & 11.0 & 3.5 & 15.5 & 5.3 \\
\hline & N of persons & 16 & & 16 & \\
\hline \multirow[t]{3}{*}{$\begin{array}{l}\text { Wave } 3 \\
\text { (Dec 2010) }\end{array}$} & $\begin{array}{l}\text { Activity area } \\
\text { Area }\left(\mathrm{km}^{2}\right) \text { area }\left(\mathrm{km}^{2}\right)\end{array}$ & 6.4 & 6.4 & 14.1 & 10.1 \\
\hline & Steps & 12.4 & 3.1 & 18.2 & 3.9 \\
\hline & $N$ of persons & 19 & & 13 & \\
\hline \multirow[t]{3}{*}{$\begin{array}{l}\text { Wave } 4 \\
\text { (Mar 2011) }\end{array}$} & $\begin{array}{l}\text { Activity area } \\
\text { Area }\left(\mathrm{km}^{2}\right) \text { area }\left(\mathrm{km}^{2}\right)\end{array}$ & 16.0 & 30.9 & 61.4 & 155.8 \\
\hline & Steps & 11.2 & 4.1 & 15.5 & 4.3 \\
\hline & $N$ of persons & 15 & & 14 & \\
\hline
\end{tabular}

${ }^{\text {a }}$ Measured in $\mathrm{km}^{2}$

${ }^{\mathrm{b}}$ Measured in $10^{3}$ steps/day

results. Male participants spent significantly more time on outdoor activities than the female participants in all four waves. The former spent more time than the latter for other activities, such as chatting with other people, eating and drinking, and resting in Waves 1 and 2. Meanwhile, female participants spent significantly more time on indoor activities, such as weaving and doing housework in all four waves.

Table 5 summarizes results of the Pearson's correlation analysis. The area of activity space and counts of daily steps were positively significantly correlated. The $r$ of 0.539 is moderate to strong correlation with a high statistical significance $(p<0.01)$. In addition, time spent on indoor activities such as weaving and doing housework was negatively significantly associated with daily steps and activity space. An $r$ of -0.395 is weak to moderate correlation with a high statistical significance $(p<0.01)$. Time spent on outdoor activities such as cultivating rice, fishing, livestock grazing, and hunting and gathering was also positively significantly associated with daily steps and activity space. The $r$ of 0.282 is weak correlation with a high statistical significance $(p<0.01)$ (Additional file 1 : Table S1).

\section{Regression model results}

Based on the bivariate analysis results, two linear mixed models were developed for daily steps and activity space, respectively. The fixed effects included observations of participant's characteristics such as age and gender, time spent on outdoor activities, and distance from home to 
Table 3 ANOVA results of activity space and total steps by gender and by wave

\begin{tabular}{|c|c|c|c|c|c|c|}
\hline \multirow[t]{2}{*}{ Wave } & & \multicolumn{2}{|c|}{ Female } & \multicolumn{2}{|l|}{ Male } & \multirow{2}{*}{$\begin{array}{l}\text { ANOVA } \\
p \text { value }\end{array}$} \\
\hline & & Mean & SD & Mean & SD & \\
\hline \multirow{2}{*}{$\begin{array}{l}\text { Wave } 1 \\
\text { (Jun 2010) }\end{array}$} & LN (2SD SQM) ${ }^{\mathrm{a}}$ & 0.75 & 2.03 & 2.33 & 1.75 & 0.030 \\
\hline & LN (daily steps) ${ }^{b}$ & 9.44 & 0.23 & 9.90 & 0.30 & 0.001 \\
\hline \multirow{2}{*}{$\begin{array}{l}\text { Wave } 2 \\
\text { (Sep 2010) }\end{array}$} & LN (2SD SQM) & -0.08 & 2.16 & 1.42 & 2.21 & 0.062 \\
\hline & LN (daily steps) & 9.24 & 0.38 & 9.58 & 0.42 & 0.026 \\
\hline \multirow{2}{*}{$\begin{array}{l}\text { Wave } 3 \\
\text { (Dec 2010) }\end{array}$} & LN (2SD SQM) & 0.66 & 2.22 & 1.97 & 1.82 & 0.090 \\
\hline & LN (daily steps) & 9.40 & 0.25 & 9.78 & 0.24 & 0.001 \\
\hline \multirow{2}{*}{$\begin{array}{l}\text { Wave } 4 \\
\text { (Mar 2011) }\end{array}$} & LN (2SD SQM) & -0.19 & 2.95 & 2.33 & 1.69 & 0.010 \\
\hline & LN (daily steps) & 9.26 & 0.38 & 9.62 & 0.27 & 0.007 \\
\hline
\end{tabular}

$P$ value $<0.1$ are shown italic

$P$ value $<0.05$ are shown bold

${ }^{a}$ LN (2SD SQM): natural log transformation of activity space

${ }^{b}$ LN (daily steps): natural log transformation of counts of daily steps

Table 4 ANOVA results for self-reported time for different activities between 6 am and 6 pm by gender by wave (h/day)

\begin{tabular}{|c|c|c|c|c|c|c|}
\hline \multirow[t]{2}{*}{ Wave } & \multirow[t]{2}{*}{ Activity } & \multicolumn{2}{|c|}{ Female } & \multicolumn{2}{|l|}{ Male } & \multirow{2}{*}{$\begin{array}{l}\text { ANOVA } \\
p \text { value }\end{array}$} \\
\hline & & Mean & SD & Mean & SD & \\
\hline \multirow[t]{3}{*}{ Wave 1} & Outdoor activities & 3.4 & 2.3 & 6.0 & 1.9 & 0.002 \\
\hline & Indoor activities & 4.2 & 2.3 & 0.5 & 0.8 & 0.001 \\
\hline & Other activities & 4.4 & 1.0 & 5.5 & 1.6 & 0.027 \\
\hline \multirow[t]{3}{*}{ Wave 2} & Outdoor activities & 1.6 & 1.4 & 4.8 & 2.1 & 0.001 \\
\hline & Indoor activities & 5.8 & 2.0 & 0.6 & 0.8 & 0.001 \\
\hline & Other activities & 4.6 & 1.3 & 6.6 & 2.1 & 0.003 \\
\hline \multirow[t]{3}{*}{ Wave 3} & Outdoor activities & 2.7 & 2.1 & 4.9 & 2.5 & 0.013 \\
\hline & Indoor activities & 4.5 & 2.4 & 1.7 & 1.7 & 0.001 \\
\hline & Other activities & 4.7 & 1.0 & 5.4 & 1.6 & 0.149 \\
\hline \multirow[t]{3}{*}{ Wave 4} & Outdoor activities & 1.7 & 1.2 & 4.2 & 2.3 & 0.001 \\
\hline & Indoor activities & 5.3 & 2.1 & 2.9 & 2.2 & 0.005 \\
\hline & Other activities & 5.0 & 1.5 & 5.0 & 1.5 & 0.953 \\
\hline
\end{tabular}

$P$ value $<0.05$ are shown bold

Table 5 Pearson correlation results

\begin{tabular}{lcc}
\hline & $\begin{array}{c}\text { Daily steps } \\
\text { (Natural log transformed) }\end{array}$ & $\begin{array}{c}\text { Activity space } \\
\text { (Natural log } \\
\text { transformed) }\end{array}$ \\
\hline Activity space (natural log transformed) & $0.539^{* * *}$ \\
Time spent on indoor activities (weaving and doing housework) & $-0.518^{* * *}$ & $-0.395^{* * *}$ \\
Time spent on outdoor activities (fishing, livestock grazing, and hunting and gathering) & $0.353^{* * *}$ & -0.137 \\
Time spent on other activities (chatting with others, eating and drinking, and resting) & $0.490^{* * *}$ & $0.282^{* * *}$ \\
Time spent on rice cultivating & -0.030 & 0.147 \\
Distance from home to paddy & $0.186^{* *}$ \\
\hline
\end{tabular}

$* * * p$ value $<0.01$

${ }^{* *} p$ value $<0.05$ 
Table 6 Linear mixed model results (fixed effect)—daily steps and activity space

\begin{tabular}{|c|c|c|c|c|}
\hline & \multicolumn{2}{|c|}{$\begin{array}{l}\text { Daily steps } \\
\text { (Natural log- } \\
\text { transformed) }\end{array}$} & \multicolumn{2}{|c|}{$\begin{array}{l}\text { Activity space } \\
\text { (Natural log- } \\
\text { transformed) }\end{array}$} \\
\hline & $B$ & $p$ value & $B$ & $p$ value \\
\hline (Constant) & 9.262 & 0.000 & 2.104 & 0.015 \\
\hline Gender (male vs. female) & 0.172 & 0.009 & 1.368 & 0.004 \\
\hline Age & -0.003 & 0.306 & -0.069 & 0.002 \\
\hline Outdoor ${ }^{\mathrm{a}}$ activity time & 0.081 & 0.000 & 0.194 & 0.052 \\
\hline $\begin{array}{l}\text { Distance }{ }^{b} \text { from home to paddy } \\
(\mathrm{km})\end{array}$ & -0.043 & 0.092 & 0.130 & 0.455 \\
\hline Wave 1 & 0.142 & 0.030 & 0.295 & 0.587 \\
\hline Wave 2 & -0.003 & 0.962 & -0.443 & 0.398 \\
\hline Wave 3 & 0.113 & 0.054 & 0.068 & 0.894 \\
\hline Wave $4^{c}$ & 0.000 & & & \\
\hline
\end{tabular}

$P$ value $<0.1$ are shown bold and italic

$P$ value $<0.05$ are shown bold

${ }^{\text {a }}$ Time spent on outdoor activities, such as rice cultivating, fishing, livestock grazing, and hunting and gathering

${ }^{\mathrm{b}}$ Distance from home to paddy field in $\mathrm{km}$

'Reference category

participant's paddy field. Wave information was also added into the model as a category variable using Wave 4 as the reference. The individual participants were included as the random effect to control for variations of individual participants. Table 6 summarizes the linear mixed model results. Females were found to have significantly fewer steps and smaller activity space compared with those of their male counterparts. Age was negatively significantly associated with activity space only. As expected, time spent on outdoor activities was positively significantly associated with steps and activity space. Compared with Wave 4, participants in Waves 1 have significantly more daily steps, and participants in Wave 3 showed a positive marginal significance. No significant difference was found for activity space among different waves.

\section{Discussion}

Our findings showed that participants' daily steps and activity space were positively significantly associated with each other. In other words, with more daily steps, a participant's activity space increased. Despite some study participants owning motorcycles, the substandard road conditions required many participants to walk while performing daily activities. Examples include rice cultivating, paddy fishing, livestock grazing, and individual hunting and gathering. These activities, measured by step count, are also consistent with our field observations. Taken together, these results imply that our study participants were more likely to travel on foot for their daily activities. This is quite different from studies in the U.S. and China, where driving and car ownership are associated with larger activity space $[41,45]$. These findings underscore the importance of identifying place-based solutions to public health challenges [39], especially in developing Southeast Asian countries.

Although study participants traveled mostly by foot, female participants were found to have significantly fewer daily steps and smaller activity spaces than those of the male participants. This finding is similar to the findings in other countries, where an increasing gender gap of physical activity has been observed [5, 46-48]. Our study also found that one-fourth of the female participants and one-eighth of male participants were overweight with BMIs greater than $25 \mathrm{~kg} / \mathrm{m}^{2}$. Despite finding lower overweight rates among male participants, these results were consistent with a LAO PDR STEPS report conducted by the World Health Organization [49]. Our findings suggest that analyses of activity space would be able to evaluate risks of obesity in paddy farming communities.

The division of labor in our study area may be the core issue of this finding. For instance, male participants were found to spend much more time on outdoor activities including rice cultivating, fishing, and livestock grazing. Female participants, on the other hand, spent the majority of their time on indoor activities, such as weaving and housework. Our findings are consistent with the previous studies on labor division in Lao PDR [50]. Surprisingly, despite walking being the most frequent travel mode in the study area, there are still a few participants with daily steps fewer than 10,000, an important indicator for an active lifestyle $[43,44]$. One explanation, as shown in Table 4, is that both male and female participants spent more than one-third of their day on sedentary or lowlevel physical activities, such as chatting, resting, drinking or eating. However, females spent more time on low-level physical activity indoors, such as weaving and housework. Therefore, with gyms, parks, and other public spaces not readily available in the region, it is difficult for rural Southeast Asians to increase physical activity in a subsistence lifestyle. Thus, future studies and intervention programs could focus on how to incorporate physical activities into leisure time to promote healthier lifestyles, particularly for rural Southeast Asian females, as males tend to receive more physical activity from their work in the region.

Activity space was not found to have significant seasonal variations. On the other hand, when comparing physical activities of different farming seasons, participants in Wave 1 (wet farming season) and Wave 3 (dry farming season) were found to have more daily steps 
than those participants in Wave 4 (dry off-farming season). These findings indicated that village residents have their routine destinations and physical activity levels of residents in the region are strongly impacted by farming. In other words, frequency of visiting those routine destinations show seasonal variations, with farming seasons having higher frequent visits than dry off-farming season. This evidence demonstrates that seasonal variation does impact rural resident activities in mainland Southeast Asia. Thus, future interventions aimed at increasing physical activity should prioritize the off-farming season, where subsistence work is reduced and residents are less physically active.

Our study also has a number of limitations. For instance, the sample size is relatively small. Moreover, our study only collected data for 1 year. Longitudinal studies with historical data and larger sample sizes would bring richer insights into the health transition of developing countries. In addition, our sample represented "active" farmers rather than the "inactive" industrialized urban people, who are more at risk of obesity, in Southeast Asia. Finally, our study does not address the caloric intake of participants. As overweight and obesity are generally caused by the imbalance between calorie consumption and intake, this acts as an important distinction to address. However, our results are a useful baseline to physical activity and activity space of farmers in Southeast Asia.

\section{Conclusion}

Our study is one of the first to objectively measure activity space and physical activity to assess the impact of farming seasons in rural Southeast Asia. Physical activity levels are strongly impacted by whether residents farm or not in the region. Integrating GPS tracking and accelerometer data to depict an activity space, where individuals travel and how much time they spent on different daily activities allows for advances in assessing the health risk factors of both communicable and non-communicable diseases. Understanding daily travel activities in this way may contribute to effective intervention programs needed to create healthy living environments $[51,52]$. On the one hand, it improves the awareness for the necessity of physical activity. On the other, it creates a method to provide affordable equipment to assess physical activity with limited public health resources in Southeast Asia.

\section{Supplementary Information}

The online version contains supplementary material available at https://doi. org/10.1186/s41182-021-00364-6.

Additional file 1. ANOVA results of activity space and total steps by age category and by wave.

\section{Acknowledgements}

We are grateful to the villagers of Lahanam Area, Songkhon District Lao PDR, as well as to Mr. Futoshi Nishimoto of Embassy of Japan in the Lao PDR, our colleagues at Lao Tropical and Public Health Institution, the Savannakhet Provincial Department of Health for their participation and assistance with the study.

\section{Authors' contributions}

KM and HWJ acquired research grants. HWJ, KM, TP, SK designed the study. $H W J, T P, S K$ conducted the field survey, HWJ prepared the data sets. HWJ, LL, and DY conducted the analysis and drafted the manuscript. All authors read and approved the final manuscript.

\section{Funding}

Japanese Research Institute for Humanity and Nature research project "Environmental Change and Infectious Diseases in Tropical Asia". And Japanese National Institutes for the Humanities Transdisciplinary Project "New Development in Ecohealth in Asia" supported the general research plan design, field survey, data and material collection. JSPS KAKENHI Grant-in-Aid for Scientific Research A (Grant No. 25257004) and JSPS KAKENHI Grant-in-Aid for Scientific Research C (Grant No. 17K02061) supported the data processing, data analysis and supplementary survey. Research Institute for Humanity and Nature will cover the open access publication fees.

\section{Availability of data and materials}

The data sets used and/or analyzed during the current study are available from the corresponding author on reasonable request.

\section{Declarations}

\section{Ethics approval and consent to participate}

Ethics approval was granted by the Ethics Review Committee at the Research Institute for Humanity and Nature (Research Ethics Review Committee Reference Number: No. RIHN-2007-03). Written informed consent is obtained from all participants prior to data collection.

\section{Consent for publication}

Not applicable.

\section{Competing interests}

The authors declare no competing interests.

\section{Author details}

${ }^{1}$ Research Institute for Humanity and Nature, 457-4 Motoyama, Kamigamo, Kita-ku, Kyoto 603-8047, Japan. ${ }^{2}$ Department of Urban Planning and Design, Xi'an Jiaotong - Liverpool University, Suzhou, Jiangsu Province, China. ${ }^{3}$ Department of Geography, The University of Alabama, Tuscaloosa, AL, USA. ${ }^{4}$ Savannakhet Provincial Health Department, Savannakhet city, Savannakhet Province, Lao PDR. ${ }^{5}$ Lao Tropical and Public Health Institution, Vientiane, Lao PDR. ${ }^{6}$ School of Tropical Medicine and Global Health, Nagasaki University, Nagasaki City, Japan.

Received: 26 June 2021 Accepted: 6 September 2021

Published online: 16 September 2021

\section{References}

1. WHO. Noncommunicable diseases country profiles 2018. Geneva: World Health Organization; 2018; [Cited Jun 23, 2021]. https://apps.who.int/iris/

handle/10665/274512.

\footnotetext{
BMI: Body Mass Index; NCD: Non-communicable disease; GPS: Global poisoning system; IPAQ: International Physical Activity Questionnaire; GPAQ: Global Physical Activity Questionnaire; SDE: Standard deviation ellipse.
} 
2. Dans A, Ng N, Varghese C, Tai ES, Firestone R, Bonita R. Health in Southeast Asia 4 The rise of chronic non-communicable diseases in southeast Asia: time for action. Lancet. 2011;377(9766):680-9.

3. Lee IM, Shiroma EJ, Lobelo F, Puska P, Blair SN, Katzmarzyk PT, et al. Effect of physical inactivity on major non-communicable diseases worldwide: an analysis of burden of disease and life expectancy. Lancet. 2012;380(9838):219-29.

4. Booth FW, Roberts CK, Laye MJ. Lack of exercise is a major cause of chronic diseases. Compr Physiol. 2012:2(2):1143-211.

5. Guthold R, Stevens GA, Riley LM, Bull FC. Worldwide trends in insufficient physical activity from 2001 to 2016: a pooled analysis of 358 population-based surveys with 1.9 million participants. Lancet Glob Health. 2018;6(10):e1077-86.

6. Waxman A. WHO global strategy on diet, physical activity and health. Food Nutr Bull. 2004;25(3):292-302.

7. Patterson PD, Moore CG, Probst JC, Shinogle JA. Obesity and physical inactivity in rural America. J Rural Health. 2004;20(2):151-9.

8. Win AM, Yen LW, Tan KH, Lim RB, Chia KS, Mueller-Riemenschneider F. Patterns of physical activity and sedentary behavior in a representative sample of a multi-ethnic South-East Asian population: a cross-sectional study. BMC Public Health. 2015;15:318.

9. Hallal PC, Andersen LB, Bull FC, Guthold R, Haskell W, Ekelund U, et al. Global physical activity levels: surveillance progress, pitfalls, and prospects. Lancet. 2012;380(9838):247-57.

10. WHO. Preventing Chronic Diseases: A Vital Investment. Geneva: World Health Organization; 2005; [Cited Jun 23, 2021]. https://apps.who.int/iris/ handle/10665/43314.

11. Ezzati M, Pearson-Stuttard J, Bennett JE, Mathers CD. Acting on non-communicable diseases in low- and middle-income tropical countries. Nature. 2018;559(7715):507-16.

12. Bowling A. Mode of questionnaire administration can have serious effects on data quality. J Public Health (Oxf). 2005;27(3):281-91.

13. Ng N, Hakimi M, Van Minh H, Juvekar S, Razzaque A, Ashraf A, et al. Prevalence of physical inactivity in nine rural INDEPTH Health and Demographic Surveillance Systems in five Asian countries. Glob Health Action. 2009;2:1.

14. Guthold R, Ono T, Strong KL, Chatterji S, Morabia A. Worldwide variability in physical inactivity a 51-country survey. Am J Prev Med. 2008;34(6):486-94.

15. Brage S, Wedderkopp N, Franks PW, Andersen LB, Froberg K. Reexamination of validity and reliability of the CSA monitor in walking and running. Med Sci Sports Exerc. 2003;35(8):1447-54

16. Schneider PL, Crouter S, Bassett DR. Pedometer measures of free-living physical activity: comparison of 13 models. Med Sci Sports Exerc. 2004;36(2):331-5.

17. Troiano RP, Berrigan D, Dodd KW, Masse LC, Tilert T, McDowell M. Physical activity in the United States measured by accelerometer. Med Sci Sports Exerc. 2008;40(1):181-8.

18. Oyeyemi AL, Umar M, Oguche F, Aliyu SU, Oyeyemi AY. Accelerometerdetermined physical activity and its comparison with the International Physical Activity Questionnaire in a sample of Nigerian adults. PLOS ONE. 2014;9(1):e87233.

19. Craig CL, Marshall AL, Sjostrom M, Bauman AE, Booth ML, Ainsworth BE, et al. International physical activity questionnaire: 12 -country reliability and validity. Med Sci Sports Exerc. 2003;35(8):1381-95.

20. Sobngwi E, Mbanya JC, Unwin NC, Aspray TJ, Alberti KG. Development and validation of a questionnaire for the assessment of physical activity in epidemiological studies in Sub-Saharan Africa. Int J Epidemiol. 2001;30(6):1361-8.

21. Villanueva K, Giles-Corti B, Bulsara M, McCormack GR, Timperio A, Middleton $\mathrm{N}$, et al. How far do children travel from their homes? Exploring children's activity spaces in their neighborhood. Health Place. 2012;18(2):263-73.

22. Kamruzzaman M, Hine J. Analysis of rural activity spaces and transport disadvantage using a multi-method approach. Transp Policy. 2012;19(1):105-20.

23. Wong DWS, Shaw SL. Measuring segregation: an activity space approach. J Geogr Syst. 2011;13(2):127-45.

24. Buliung RN, Kanaroglou PS. A GIS toolkit for exploring geographies of household activity/travel behavior. J Transp Geogr. 2006;14(1):35-51.

25. Dijst M. Action space as planning concept in spatial planning. Netherlands J Housing Built Environ. 1999;14(2):163-82.

26. Stimson RGGaRJ. Spatial behaviour: a geographic perspective. New York: Guilford Press; 1996

27. Schönfelder S. Urban rhythms: Modelling the rhythms of individual travel behaviour [Dissertation]: ETH Zurich; 2006.
28. Shoval N, Isaacson M. Application of tracking technologies to the study of pedestrian spatial behavior. Prof Geogr. 2006;58(2):172-83.

29. Modsching M, Kramer R, Gretzel U, ten Hagen K. Capturing the beaten paths: a novel method for analysing tourists' spatial behaviour at an urban destination; 2006. 75-86 p.

30. Smith L, Foley L, Panter J. Activity spaces in studies of the environment and physical activity: a review and synthesis of implications for causality. Health Place. 2019;58:1.

31. Troiano RP, McClain JJ, Brychta RJ, Chen KY. Evolution of accelerometer methods for physical activity research. Br J Sports Med. 2014;48(13):1019-23.

32. Sallis JF, Floyd MF, Rodriguez DA, Saelens BE. Role of built environments in physical activity, obesity, and cardiovascular disease. Circulation. 2012;125(5):729-37.

33. Zhou R, Li Y, Umezaki M, Ding Y, Jiang H, Comber A, et al. Association between physical activity and neighborhood environment among middleaged adults in Shanghai. J Environ Public Health. 2013;2013:239595.

34. Jankowska MM, Schipperijn J, Kerr J. A Framework for using GPS data in physical activity and sedentary behavior studies. Exerc Sport Sci Rev. 2015;43(1):48-56.

35. Carlson JA, Schipperijn J, Kerr J, Saelens BE, Natarajan L, Frank LD, et al. Locations of physical activity as assessed by GPS in young adolescents. Pediatrics. 2016;137(1):1

36. Koohsari MJ, Kaczynski AT, Hanibuchi T, Shibata A, Ishii K, Yasunaga A, et al. Physical activity environment and Japanese adults' body mass index. Int J Env Res Pub Health. 2018;15(4):1.

37. Cervero R, Sarmiento OL, Jacoby E, Gomez LF, Neiman A. Influences of built environments on walking and cycling: lessons from Bogota. Int J Sustain Transp. 2009;3(4):203-26.

38. Day K. Physical environment correlates of physical activity in developing countries: a review. J Phys Act Health. 2018;15(4):303-14.

39. Miranda JJ, Zaman MJ. Exporting "failure": why research from rich countries may not benefit the developing world. Rev Saude Publ. 2010;44(1):185-9.

40. Kosaka Y, Takeda S, Sithirajvongsa S, Xaydala K. Plant diversity in paddy fields in relation to agricultural practices in Savannakhet Province. Laos Econ Bot. 2006;60(1):49-61.

41. Hirsch JA, Winters M, Clarke P, Mckay H. Generating GPS activity spaces that shed light upon the mobility habits of older adults: a descriptive analysis. Int J Health Geogr. 2014;13:1-14.

42. Patterson Z, Farber S. Potential path areas and activity spaces in application: a review. Transport Rev. 2015;35(6):679-700.

43. Wattanapisit A, Thanamee S. Evidence behind 10,000 steps walking. J Health Res. 2017;31(3):241-8.

44. Tudor-Locke C, Bassett DR Jr. How many steps/day are enough? Preliminary pedometer indices for public health. Sports Med. 2004;34(1):1-8.

45. Tana, Kwan MP, Chai YW. Urban form, car ownership and activity space in inner suburbs: a comparison between Beijing (China) and Chicago (United States). Urban Stud. 2016;53(9):1784-802.

46. Mielke Gl, da Silva ICM, Kolbe-Alexander TL, Brown WJ. Shifting the physical inactivity curve worldwide by closing the gender gap. Sports Med. 2018:48(2):481-9.

47. AlthoffT, Sosic R, Hicks JL, King AC, Delp SL, Leskovec J. Large-scale physical activity data reveal worldwide activity inequality. Nature. 2017;547(7663):336-9.

48. Ng SW, Popkin BM. Time use and physical activity: a shift away from movement across the globe. Obes Rev. 2012;13(8):659-80.

49. WHO. Report on STEPS Survey on Non Communicable Diseases Risk Factors in Vientiane Capital city, Lao PDR: World Health Organization; 2008; [Cited Jun 23, 2021].

50. GRID GRIDC. Lao PDR Gender Profile: With support from the World Bank. GRID: Vientiane, Lao PDR; 2005; [Cited Jun 23, 2021]. https://documents1. worldbank.org/curated/en/665161468278050105/pdf/455720WP0Box331 01Gender1Report12005.pdf

51. Laosupap K, Sota C, Laopaiboon M. Factors affecting physical activity of rural Thai midlife women. J Med Assoc Thai. 2008;91(8):1269-75.

52. Khan SN, Grace SL, Oh P, Anand S, Stewart DE, Wu G, et al. A comparison of physical activity environments between south Asians and white Caucasians with coronary heart disease. Ethnic Dis. 2010;20(4):390-5.

\section{Publisher's Note}

Springer Nature remains neutral with regard to jurisdictional claims in published maps and institutional affiliations. 